\title{
Pedestrian risk from cars and sport utility vehicles - a comparative analytical study
}

\author{
C K Simms ${ }^{1 *}$ and D P Wood ${ }^{2}$ \\ ${ }^{1}$ Centre for Bioengineering, Department of Mechanical Engineering, Trinity College, Dublin, Ireland \\ ${ }^{2}$ Denis Wood Associates, Dublin, Ireland
}

The manuscript was received on 23 March 2006 and was accepted after revision for publication on 15 May 2006.

DOI: 10.1243/09544070JAUTO319

\begin{abstract}
Analysis of real-world crash data from the USA shows that 11.5 per cent of pedestrians struck by large sport utility vehicles (SUVs) are killed, compared with 4.5 per cent of pedestrians struck by passenger cars. The design of the vehicle front-end structure has a substantial influence on injury outcome when pedestrians are struck by vehicles. In the context of the rising population of SUVs, it is important to determine the causes of their increased hazard to pedestrians. In this paper, validated multi-body models are used to show that the shape of SUVs results in higher pedestrian injuries to the mid-body regions compared to passenger cars. Analysis shows that the mass difference between cars and SUVs is not significant for pedestrian injury causation and it is shown that an important effect of the higher front profile of SUVs is that the pedestrian is struck more centrally with respect to the body's centre of gravity, increasing the momentum transfer in the primary impact. A further important effect of the higher bonnet leading edge is that there is a direct impact to the mid-body region, which explains the significant abdomen and other internal injuries reported from real-world SUV/pedestrian impacts. By comparison, head injuries sustained from primary vehicle contact are shown to be similar or slightly lower for SUV/pedestrian impacts compared to car/ pedestrian impacts. However, real-world evidence and the current models suggest that the secondary impact with the ground is more severe in SUV/pedestrian impacts compared to car/ pedestrian impacts. Overall, these results show that the empirical finding that SUVs are more hazardous for pedestrians than passenger cars is primarily a function of the high bumper and bonnet for such vehicles.
\end{abstract}

Keywords: pedestrian safety, SUV, front-end shape, injury risk

\section{INTRODUCTION}

Pedestrian injuries and fatalities from collisions with vehicles represent about 11 per cent of all automotive casualties in the USA [1] and about 20 per cent in the EU [2]. In countries with poorer roads and where a higher percentage of travel is by foot, the proportion of automotive casualties who are pedestrians can rise to nearly 50 per cent [3], while in Ethiopia it has been reported at 85 per cent [4]. Maximizing pedestrian protection is therefore an important goal worldwide. This is best achieved by separation of

\footnotetext{
* Corresponding author: Centre for Bioengineering, Department of Mechanical Engineering, Trinity College, Parsons Building, College Green, Dublin 2, Ireland. email: csimms@tcd.ie
}

vehicular traffic from pedestrians. If a collision is unavoidable, the most important factor in determining injury severity is the impact speed [5-7]. At speeds below $20 \mathrm{~km} / \mathrm{h}$, pedestrians usually sustain only minor injuries, but above $45 \mathrm{~km} / \mathrm{h}$ collisions with pedestrians are mostly fatal $[\mathbf{8}, \mathbf{9}]$. The reason for the dominance of speed is that the collision energy increases with the square of the impact speed.

Recently, 'smart vehicles' have been developed to alert a driver to an impending collision. However, the complexity of road traffic accidents means that vehicle pedestrian accidents will continue to occur.

Finally, pedestrian safety has been improved by reducing the hazard posed by vehicle fronts. The European Transport Safety Council recommendations focus on reducing vehicle body stiffness and 
providing sufficient crush depth for the bumper, bonnet leading edge (le), and bonnet top [10]. It has also been shown that the vehicle front-end shape affects pedestrian injuries [11, 12].

Sport utility vehicles (SUVs) have significantly different mass characteristics and front shapes from passenger cars. The population of SUVs in many countries is rising rapidly, and the effect of this trend on pedestrian safety therefore needs to be assessed. In Europe, SUVs now represent 15 per cent of new vehicle registrations [13], while in the USA 40 per cent of new vehicles are either light trucks or SUVs [14]. This paper examines the effect of the mass differences and shape differences between cars and SUVs on the resulting injury patterns of struck pedestrians. The objective is to explain the real-world finding that SUVs present a substantially higher risk to pedestrians than cars in the event of a collision.

\section{REVIEW OF EMPIRICAL EVIDENCE OF SUV RISK}

Lefler and Gabler [14] used the real-world data from the USA to show that 11.5 per cent of pedestrians struck by large SUVs are killed, compared with 4.5 per cent for pedestrians struck by cars. When the data were subdivided into three impact velocity ranges $0-20,21-40$, and $41-60 \mathrm{~km} / \mathrm{h}$, light trucks and vans (LTVs - this category includes SUVs) were found to be more likely to cause AIS3+ injury than cars in all three speed ranges. This effect was most pronounced at lower speeds, because the impact energy at higher speeds for all vehicle types causes serious injury or death for pedestrians. This difference between vehicle types at low/medium speeds is significant since the majority of pedestrian accidents occur below impact speeds of $50 \mathrm{~km} / \mathrm{h}[\mathbf{8}, \mathbf{1 5}]$.

Roudsari et al. found that light truck type vehicles presented a threefold higher risk of severe injuries to pedestrians than cars [16]. Ballesteros et al. used real accident data from Maryland between 1995 and 1999 to analyse pedestrian serious injuries and fatalities for different vehicle types [17]. At collision velocities below $50 \mathrm{~km} / \mathrm{h}$ the odds ratios for pedestrian risk from SUVs compared to cars were 1.97 for traumatic brain injury, 2.0 for thoracic injury, and 2.5 for abdominal injuries. They concluded that 'the increased risks to pedestrians of LTVs compared to cars may be due to their increased mass and speed'. However, the breakdown of vehicle type in their sample was questionable: only 4.5 per cent of cases actually involved an SUV, compared to 66 per cent of cases involving cars.
Longhitano et al. [18] used the Pedestrian Crash Data Study (PCDS) to analyse the influence of vehicle body type on pedestrian injury distribution, and found AIS3+ head injuries in 71 per cent of cases for car impacts compared to 81 per cent of cases for LTVs. Ground impact injuries were excluded in this study. By comparison, AIS3+ injuries of the midbody regions were found in car impacts in only 25 per cent of cases, compared to 60 per cent of cases for LTVs.

Roudsari et al. [19] also used the PCDS to analyse 3146 injuries among 386 pedestrians. There was no significant difference in mean impact speed between LTVs and passenger cars. There were 159 adults with head injuries, of which 46 were struck by LTVs, making the statistical distribution between vehicle types much better than for Ballesteros et al. [17]. They reported that the likelihood of adult head injuries was minimally higher for LTVs (54 per cent) than car crashes (46 per cent) $(p=0.16)$. In addition, 39 per cent of head injuries from LTV impacts were attributed to the secondary ground impact, compared to only 7 per cent for cars. The likelihood of thorax injuries was considerably higher for LTV crashes (37 per cent) than for cars (20 per cent) $(p=0.001)$. The likelihood of abdomen injuries was also considerably higher for LTV crashes (33 per cent) than for cars (18 per cent) $(p=0.003)$. These authors did not report on the isolated risk of pelvis injuries.

These empirical studies clearly show a substantially increased risk for pedestrians when struck by a light truck, van, or SUV compared to a passenger car. However, there is clearly conflicting evidence regarding the relative risk of head injuries from different vehicle types [17-19], and there is also no agreement on the source of the increased risk of LTVs for pedestrians.

\section{VEHICLE FACTORS AFFECTING PEDESTRIAN RISK}

The main vehicle factors that influence pedestrian risk are mass, geometry, and stiffness. Lefler and Gabler [14] stated that pedestrians are at a severe disadvantage regardless of the mass of the striking vehicle and suggested that frontal geometry may be the controlling factor for pedestrian risk, but they did not elaborate on this. Ballesteros et al. [17] stated that the increased danger to pedestrians from SUVs is due to their higher mass and faster travel speeds (impact speed was not available, but in their study $\mathrm{SUV} /$ pedestrian collisions occurred in areas with 
higher speed limits). They state that the higher bumper and bonnet heights in SUVs are important because they dictate the initial contact points between pedestrians and vehicles. However, they do not comment on the reduced eccentricity of impact with respect to the pedestrian's centre of mass and the effect this has on momentum transfer in the case of an SUV collision with a pedestrian. Roudsari et al. [19] state that the key to understanding the pedestrian crash trajectory is the relationship between the pedestrian centre of gravity and the bonnet leading edge height, as this determines how much rotation will occur. However, they do not comment on the injurious effect that a direct impact against the pelvic/abdomen region has when a pedestrian is struck by a high-fronted vehicle. Stiffer vehicle fronts clearly aggravate pedestrian risk, but there is no information on SUV front end stiffness compared to car stiffness available.

There is therefore significant empirical evidence that SUVs pose a greater hazard to pedestrians than passenger cars $[\mathbf{1 4}, \mathbf{1 7 - 1 9}]$, but so far there has not been an adequate analysis of which vehicle factors are responsible for this risk.

\section{METHODS}

The Madymo [20] crash simulation software was used to model the collision interaction between (a) a car and a pedestrian and (b) an SUV and a pedestrian. The Madymo pedestrian model [21] was used, which was previously validated for car/ pedestrian impacts using cadaver tests [22]. As there are no published SUV/cadaver tests available with sufficient information for validation, the Polar II dummy impact tests performed by Okamoto et al. [23] were used for validation. Good kinematic biofidelity of the Polar II dummy has been found in impact with a sedan car [24] and more recently in impact with a late model SUV [25]. In both cases, the dummy response was compared to cadaver kinematics.

Okamoto et al. [23] configured the Polar II dummy in crash tests at $40 \mathrm{~km} / \mathrm{h}(11.1 \mathrm{~m} / \mathrm{s})$ with a car and an SUV respectively. They published high-speed video images at $20 \mathrm{~ms}$ intervals of the dummy/ vehicle interactions, as well as time histories of the constraint torque from the femur load cell on the struck leg. Geometric differences between the Polar II dummy and the Madymo male pedestrian model are small, and for validation purposes the Okamoto et al. tests were therefore simulated in Madymo.
The geometry of the front structure of the car and SUV used by Okamoto et al. [23] were used to locate contact surfaces representing the bumper, bonnet leading edge, and bonnet for each vehicle. The make and model of the vehicles used were not given, and therefore a number of assumptions were necessary. The mass and inertia characteristics of the vehicles were estimated based on real-world data reported by Ballesteros et al. [17] (see Table 1).

Real-world bonnet and windscreen forcedeformation characteristics were used [26], while the linear bumper and bonnet leading edge stiffness parameters from Liu et al. [6] were implemented (see Fig. 1). Identical stiffness characteristics were applied to the car and the SUV as vehicle type specific forcedeflection curves were not available. The pedestrian/ vehicle friction was set to 0.3 and vehicle braking friction was $0.75 \mathrm{~g}$. The same hysteresis and damping characteristics were applied to all pedestrian vehicle contacts for both vehicle types (see the Appendix).

The Madymo 50th percentile male pedestrian model was configured with initial conditions to match the tests of Okamoto et al. [23] (see Figs 2 and 3). The dummy faced sideways with respect to the vehicle in a walking stance, struck leg back. Minor alterations to the pedestrian model and the contact definitions are detailed in the Appendix.

Table 1 Vehicle inertial parameters used in the study

\begin{tabular}{lllll}
\hline & & \multicolumn{3}{c}{ Inertia } \\
\cline { 3 - 5 } & $\begin{array}{l}\text { Mass } \\
(\mathrm{kg})\end{array}$ & $\begin{array}{l}I_{\mathrm{xx}} \\
\left(\mathrm{kg} \mathrm{m}^{2}\right)\end{array}$ & $\begin{array}{l}I_{\mathrm{yy}} \\
\left(\mathrm{kg} \mathrm{m}^{2}\right)\end{array}$ & $\begin{array}{l}I_{\mathrm{zz}} \\
\left(\mathrm{kg} \mathrm{m}^{2}\right)\end{array}$ \\
\hline Car & 1200 & 425 & 1933 & 2020 \\
SUV & 1600 & 636 & 2995 & 3041 \\
\hline
\end{tabular}

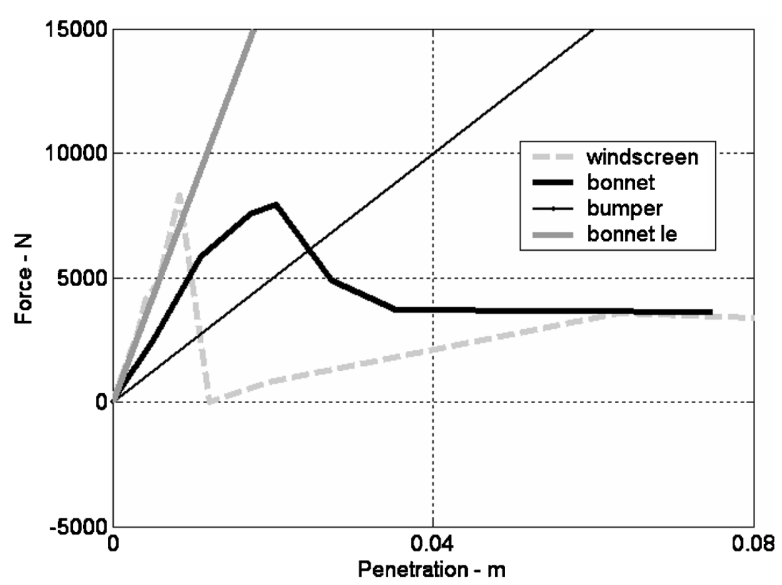

Fig. 1 Vehicle force penetration characteristics used for both cars and SUVs 

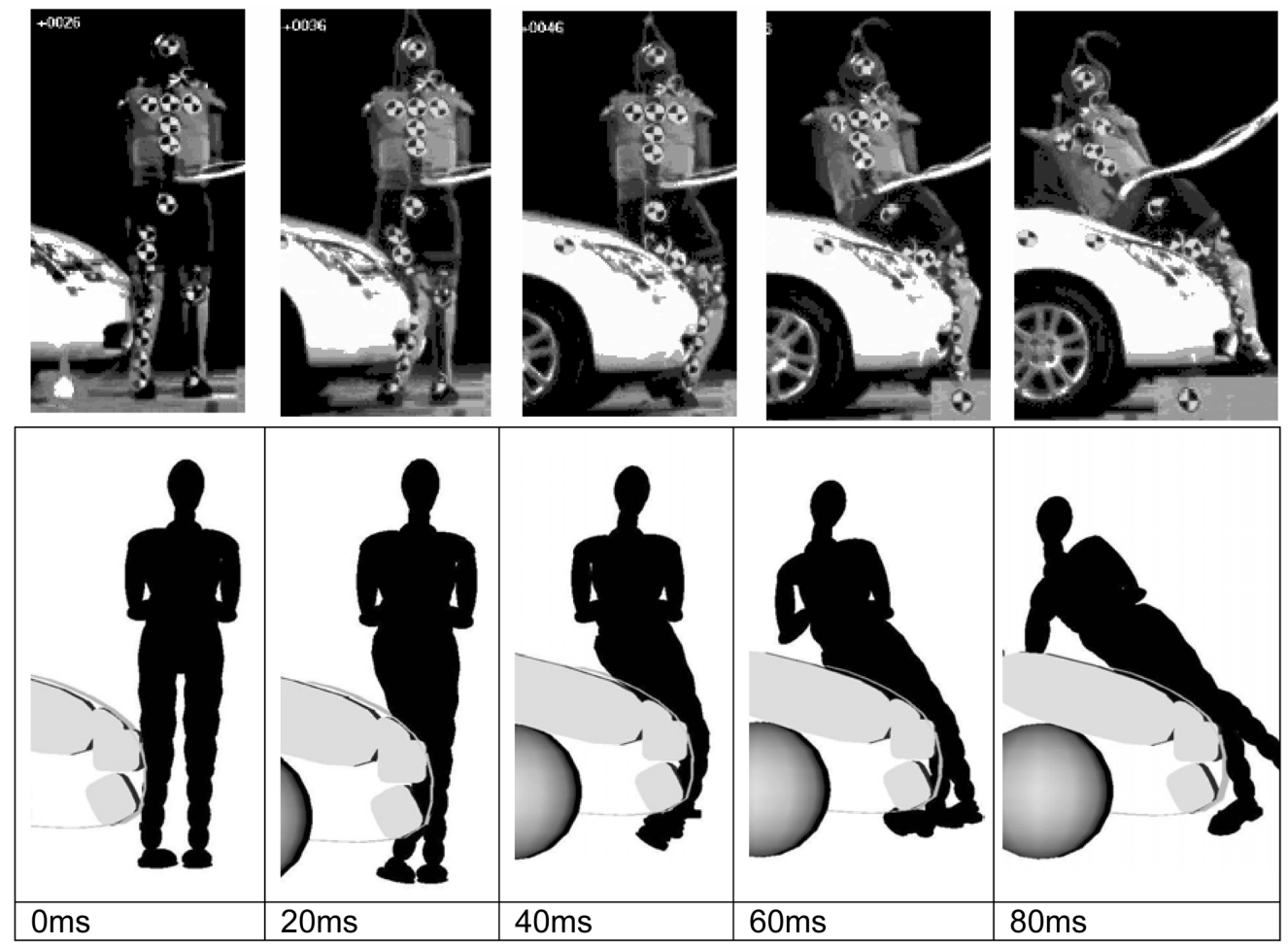

Fig. 2 Graphic sequence showing the experimental crash test between a Polar II dummy and a car [23] (top row) and the corresponding Madymo model (bottom row)
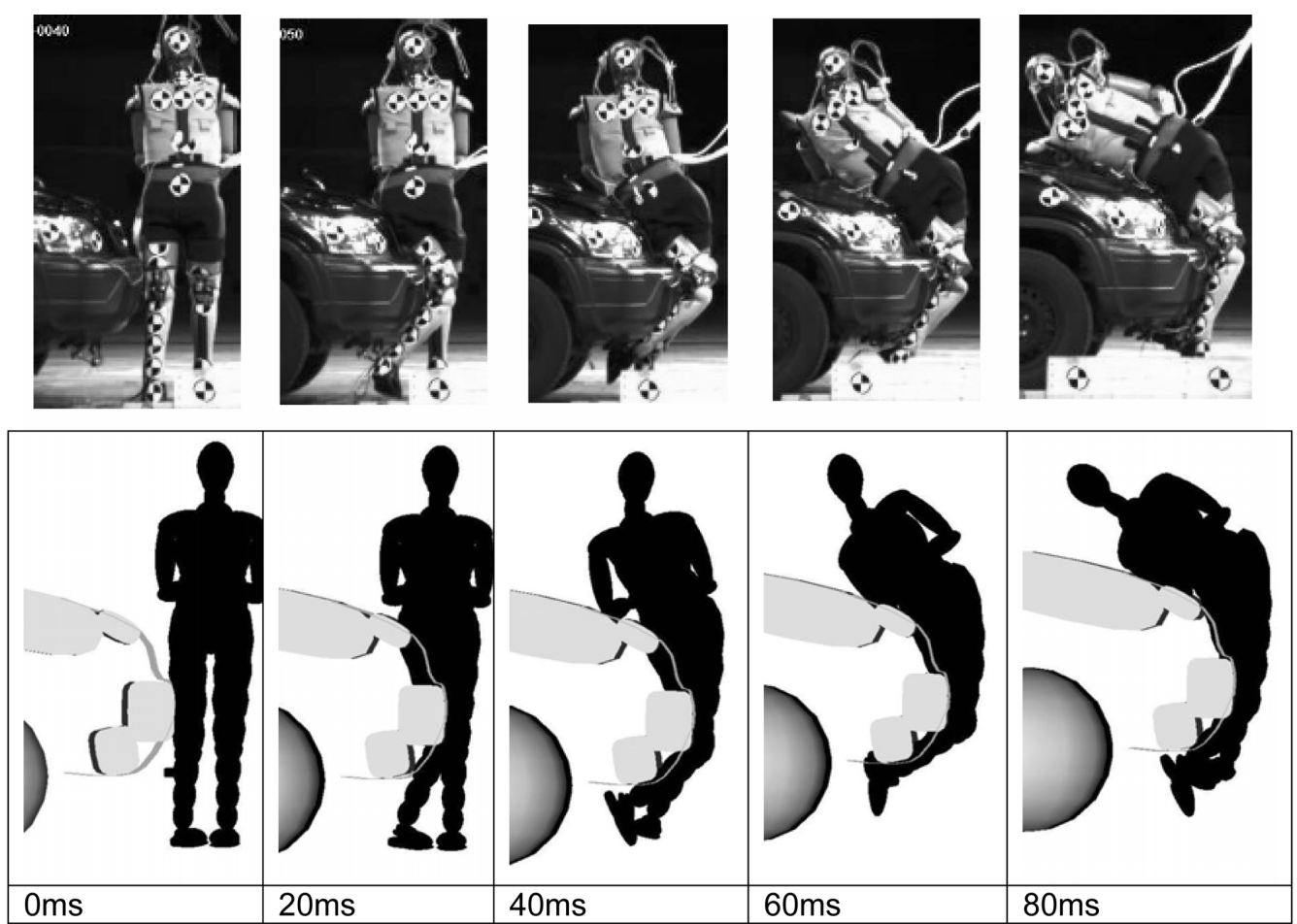

Fig. 3 Graphic sequence showing the experimental crash test between a Polar II dummy and an SUV [23] (top row) and the corresponding Madymo model (bottom row) 


\section{VALIDATION RESULTS}

Graphic results of the validations are shown in Fig. 2 (car) and Fig. 3 (SUV). There is good correspondence between the dummy and model kinematics for both vehicle types, with clear differences in pedestrian motion for the car impact compared to the SUV impact. At $20-40 \mathrm{~ms}$, the model slightly underpredicts the knee rotation in the SUV case. The upper leg joint constraint torques for both cases are shown in Fig. 4. As with the graphic comparisons, the Madymo leg shows differences to the dummy for the SUV impact at around $40 \mathrm{~ms}$, but overall the simulations predict the dummy response well. Therefore, these computational models provide a good representation of the Polar dummy interactions with both vehicle types, and the models can therefore be used to study the differences in pedestrian impact when struck by SUVs compared to cars.

\section{MODEL APPLICATION TO ASSESS CAR VERSUS SUV PEDESTRIAN RISK}

The Madymo pedestrian model was then configured with initial conditions (a) standing facing sideways to the vehicles as before (walking stance, struck leg back) and (b) standing facing toward the vehicles (see Fig. 5). Impacts were simulated at $18 \mathrm{~km} / \mathrm{h}(5 \mathrm{~m} / \mathrm{s})$, $36 \mathrm{~km} / \mathrm{h}(10 \mathrm{~m} / \mathrm{s})$, and $54 \mathrm{~km} / \mathrm{h}(15 \mathrm{~m} / \mathrm{s})$ with both the car and SUV, yielding a matrix of 12 simulations.

\subsection{Injury criteria}

Injury criteria are used to relate quantifiable parameters like acceleration and force to injuries, mainly through experiments performed with cadavers. The head injury criterion (HIC) is based on the premise that acceleration magnitude coupled with acceleration duration is well correlated with injury. It is calculated from the resultant head acceleration (measured in $g$ )

$$
\mathrm{HIC}=\max \left(t_{2}-t_{1}\right)\left[\left(\frac{1}{t_{2}-t_{1}}\right) \int_{\mathrm{t}_{1}}^{\mathrm{t}_{2}} a \mathrm{~d} t\right]^{2.5}
$$

where time is measured in seconds and the maximum time interval is $36 \mathrm{~ms}$. The HIC has many shortcomings, but an HIC of 1000 has been associated with a 50 per cent risk of skull fracture [27].

The US FMVSS 214 stipulates a peak acceleration tolerance of $1275 \mathrm{~m} / \mathrm{s}^{2}$ (130g) for the pelvis in a side impact. However, fracture tolerances vary depending on whether the load path is purely via the greater trochanter or whether the iliac crest is also loaded. For a single load path through the greater trochanter, tolerances can be as much as halved [28]. In 17 side impact tests on cadavers, Zhu et al. [29] found that the FMVSS 214 pelvis threshold acceleration was too high and reported that the peak acceleration for pelvis fracture was $716 \mathrm{~m} / \mathrm{s}^{2}(73 g)$ on average for all 17 cases, and this threshold is used to assess pelvic injury in the present work. For the abdomen,
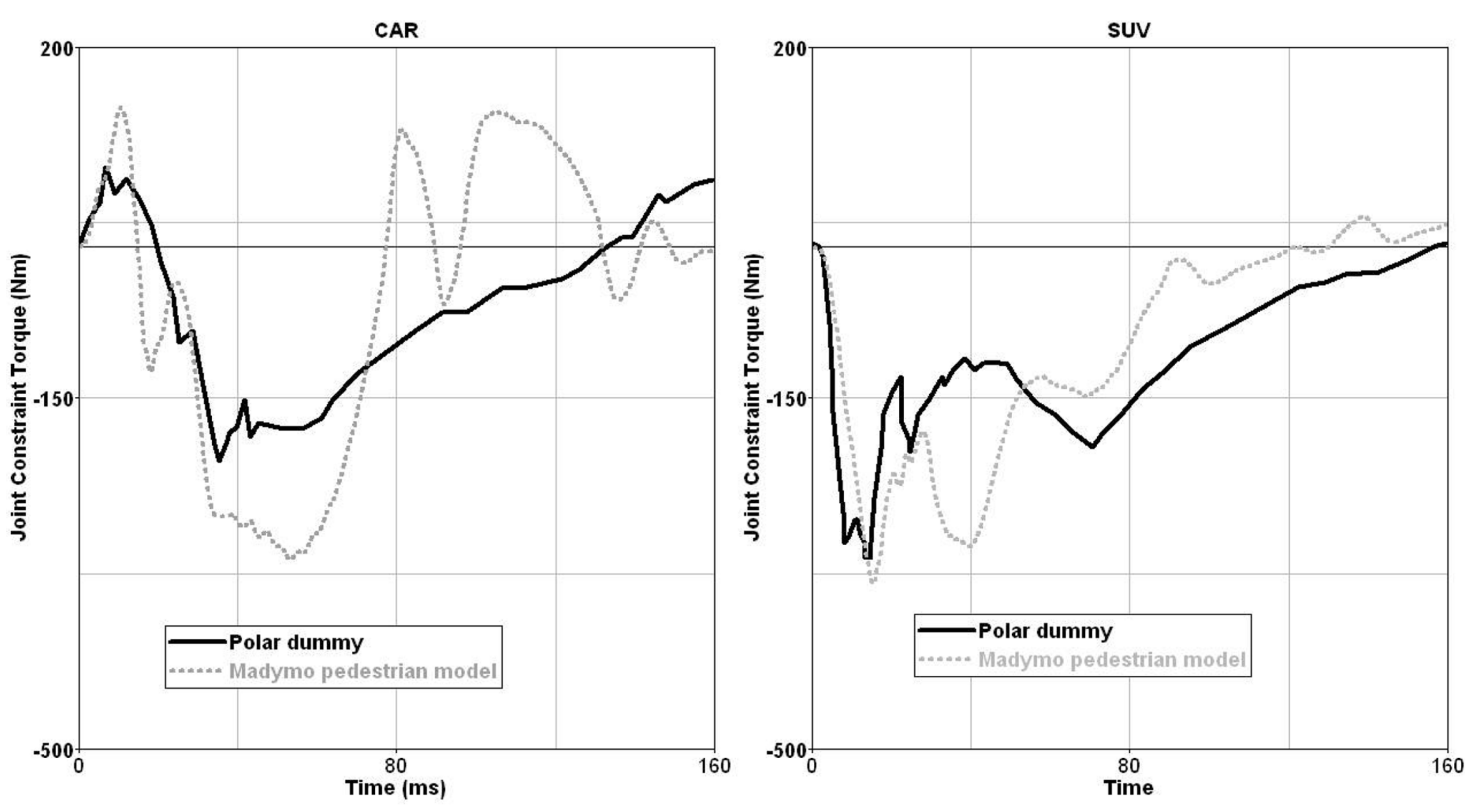

Fig. 4 Time history sequence showing upper leg joint constraint torques for car impact (left) and SUV impact (right) for both the Polar II dummy [23] and the Madymo model 


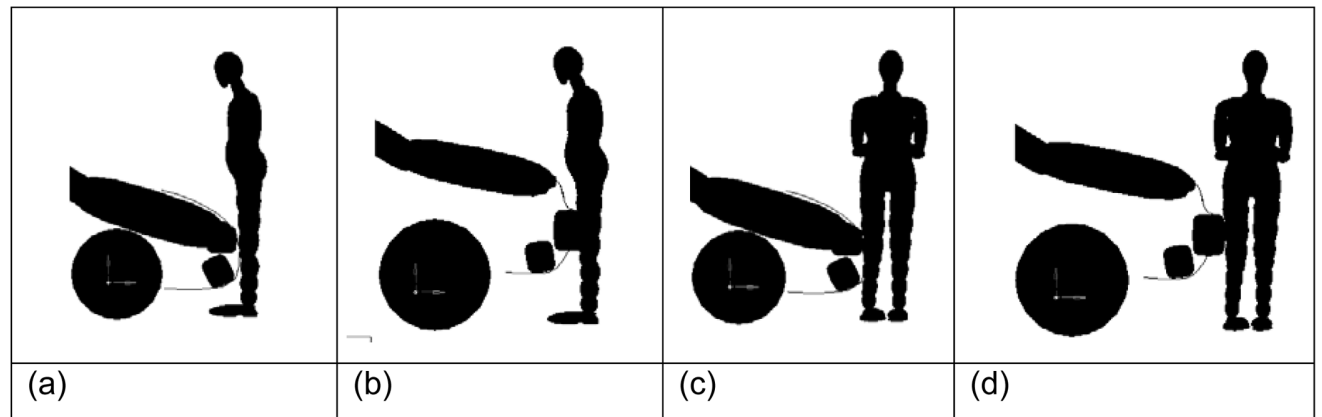

Fig. 5 Simulation matrix for (a) a pedestrian facing a car, (b) a pedestrian facing an SUV, (c) a pedestrian sideways to the car (walking stance, struck leg back), and (d) a pedestrian sideways to the SUV (walking stance, struck leg back)

Talantikite et al. $[\mathbf{3 0}]$ have reported tolerable loads on the abdomen of $4.5 \mathrm{kN}$.

A 3 ms criterion is frequently used to eliminate the effects of very short duration accelerations that may not cause injury. The $3 \mathrm{~ms}$ acceleration score is the largest resultant acceleration sustained for at least $3 \mathrm{~ms}$. For the chest, the resultant $3 \mathrm{~ms}$ acceleration threshold for injury stipulated by FMVSS 208 is $587 \mathrm{~m} / \mathrm{s}^{2}(60 \mathrm{~g})$.

These head, pelvis, abdomen, and chest injury criteria were evaluated for all of the simulations in this study. Despite being highly simplified, they are useful for evaluation of direct contact loads to the body [31]. Furthermore, as local geometry and stiffness 'hotspots' were not included in these models, the injury values give a general indication of the severity rather than a precise injury prediction. However, direct comparison between vehicle types can be made using this method.

\section{RESULTS}

Figures 6 to 8 show the $18 \mathrm{~km} / \mathrm{h}(5 \mathrm{~m} / \mathrm{s}), 36 \mathrm{~km} / \mathrm{h}$ $(10 \mathrm{~m} / \mathrm{s})$, and $54 \mathrm{~km} / \mathrm{h}(15 \mathrm{~m} / \mathrm{s})$ impact cases for the pedestrian facing forwards and sideways for both car and SUV impacts at 100, 200, and 300 ms post-impact. Figures 9, 10, and 11 show the resultant head, chest, and pelvis accelerations for the side-facing cases. The forward-facing cases are not shown to conserve space, and because 85 per cent of pedestrians have been found to be struck laterally [32].

Tables 2 to 5 show the summary data for the injury criteria for all 12 simulations. Table 2 shows the $\mathrm{HIC}_{36}$ scores for the head in the current study. Table 3 shows the peak $3 \mathrm{~ms}$ accelerations for the chest. Table 4 shows the peak pelvis accelerations and Table 5 shows the peak abdomen contact. For clarity, a response ratio for the pedestrian in the SUV impact compared to the pedestrian in the car impact is also shown for all cases. The gaps in Table 5 correspond to cases where there was no direct vehicle impact with the abdomen.

\section{DISCUSSION}

In this paper, validated simulations were developed to study the differences in pedestrian/vehicle interactions when struck by an SUV compared to a car.

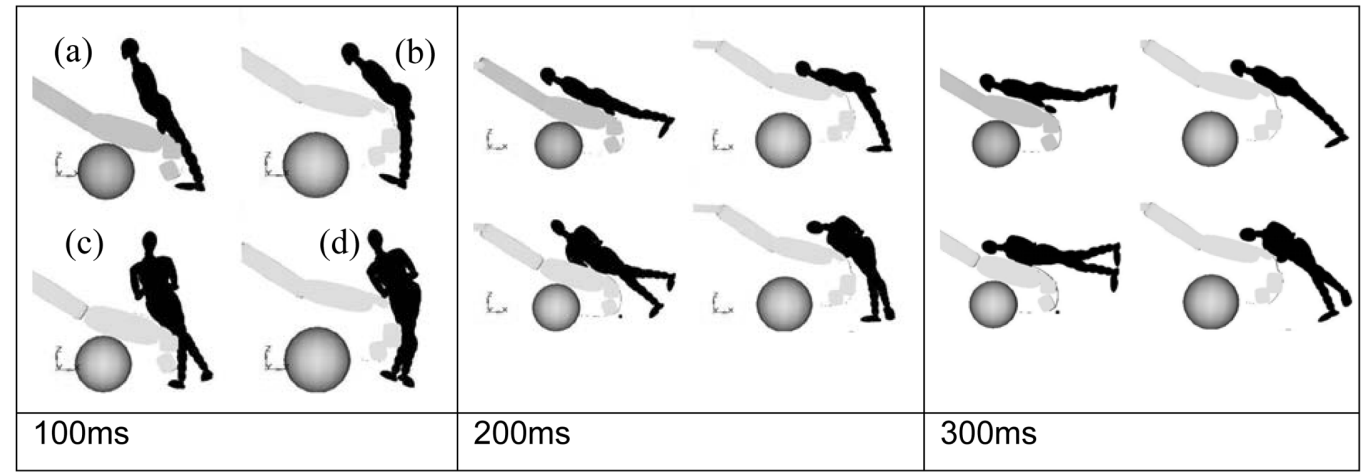

Fig. $618 \mathrm{~km} / \mathrm{h}(5 \mathrm{~m} / \mathrm{s})$ impact snapshots for (a) a pedestrian facing a car, (b) a pedestrian facing an SUV, (c) a pedestrian sideways to the car, and (d) a pedestrian sideways to the SUV at $100 \mathrm{~ms}$ intervals 


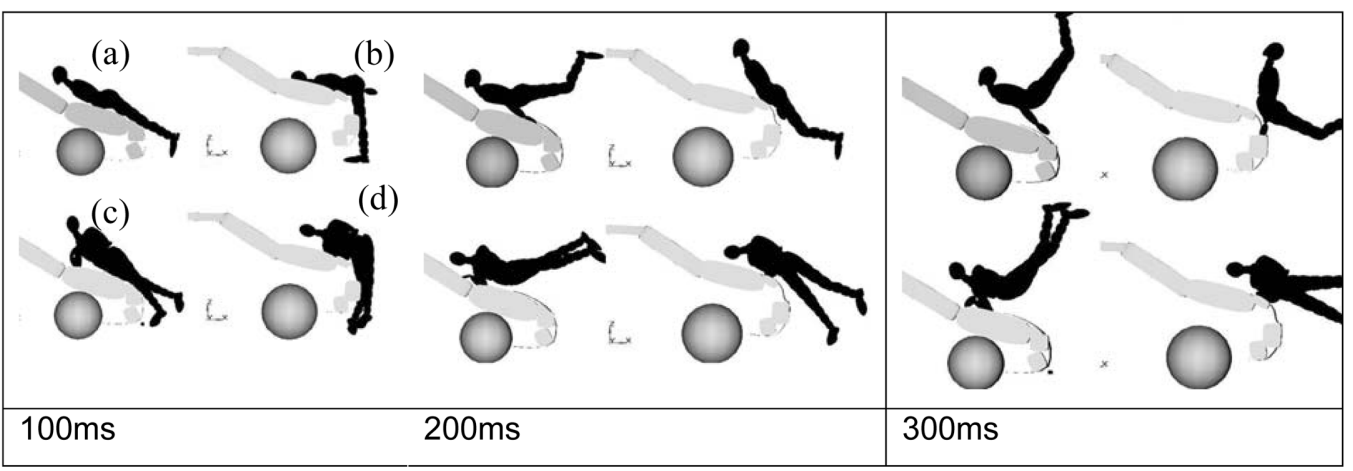

Fig. $736 \mathrm{~km} / \mathrm{h}(10 \mathrm{~m} / \mathrm{s})$ snapshots for (a) a pedestrian facing a car, (b) a pedestrian facing an SUV, (c) a pedestrian sideways to the car, and (d) a pedestrian sideways to the SUV at $100 \mathrm{~ms}$ intervals

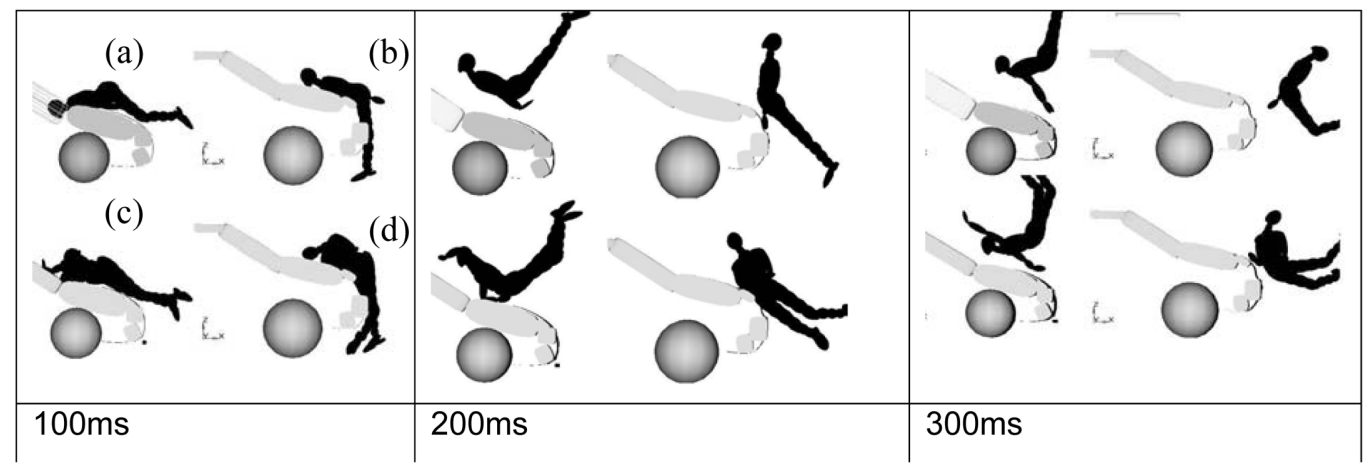

Fig. $854 \mathrm{~km} / \mathrm{h}(15 \mathrm{~m} / \mathrm{s})$ snapshots for (a) a pedestrian facing a car, (b) a pedestrian facing an SUV, (c) a pedestrian sideways to the car, and (d) a pedestrian sideways to the SUV at $100 \mathrm{~ms}$ intervals
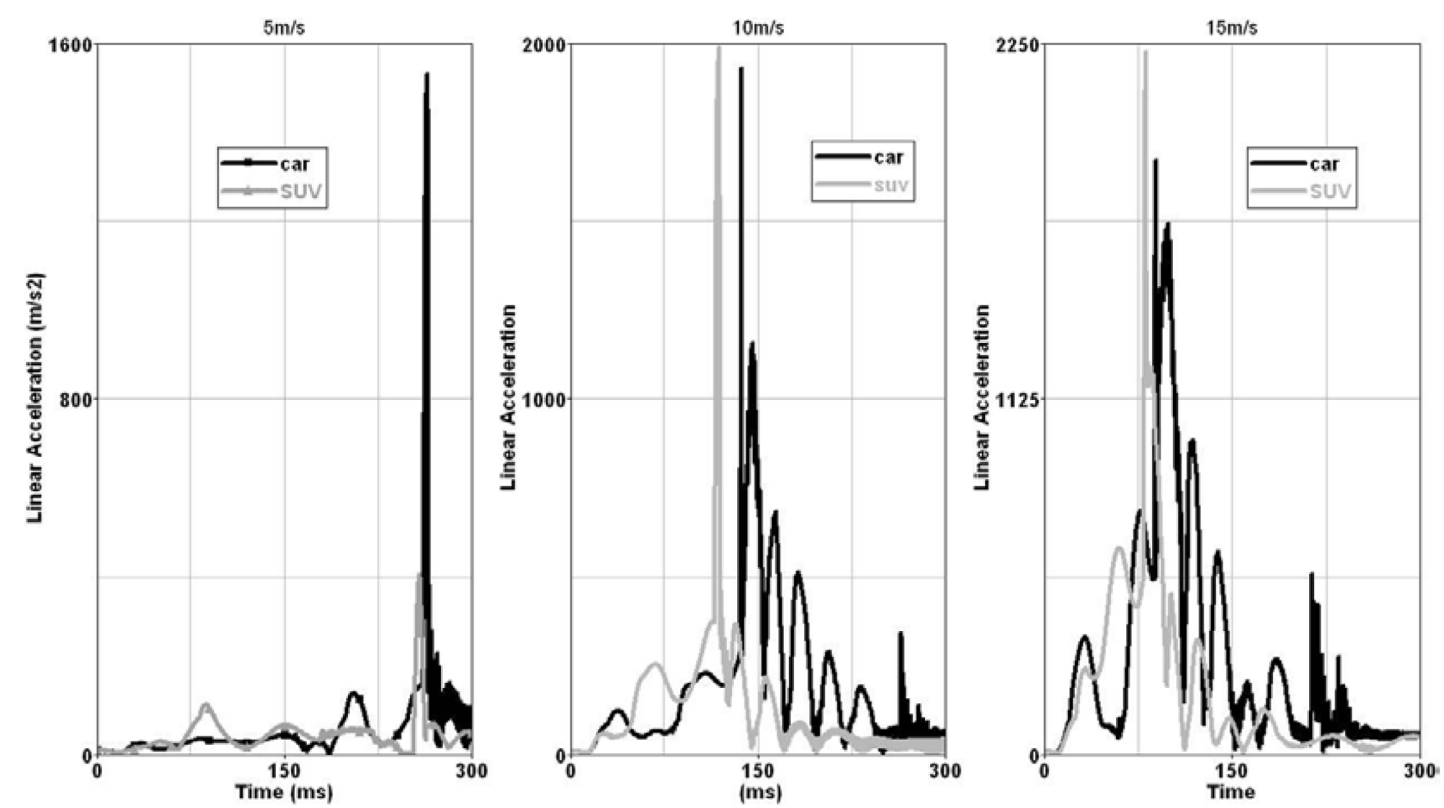

Fig. 9 Time histories of head resultant accelerations for a side-facing pedestrian struck by a car/SUV at $18 \mathrm{~km} / \mathrm{h}(5 \mathrm{~m} / \mathrm{s}), 36 \mathrm{~km} / \mathrm{h}(10 \mathrm{~m} / \mathrm{s})$, and $54 \mathrm{~km} / \mathrm{h}(15 \mathrm{~m} / \mathrm{s})$ 

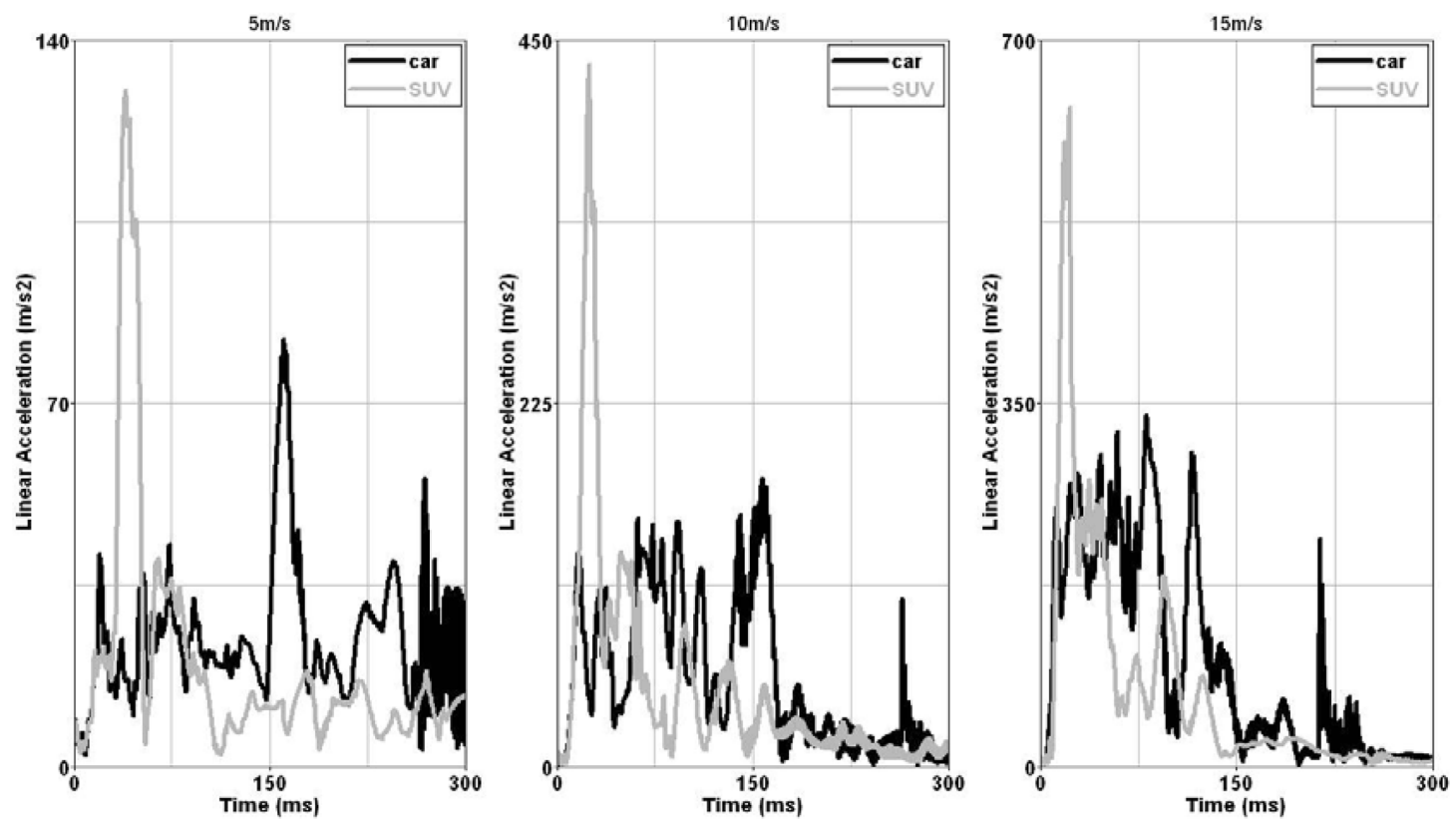

Fig. 10 Time histories of chest resultant accelerations for a side-facing pedestrian struck by a car/SUV at $18 \mathrm{~km} / \mathrm{h}(5 \mathrm{~m} / \mathrm{s}), 36 \mathrm{~km} / \mathrm{h}(10 \mathrm{~m} / \mathrm{s})$, and $54 \mathrm{~km} / \mathrm{h}(15 \mathrm{~m} / \mathrm{s})$
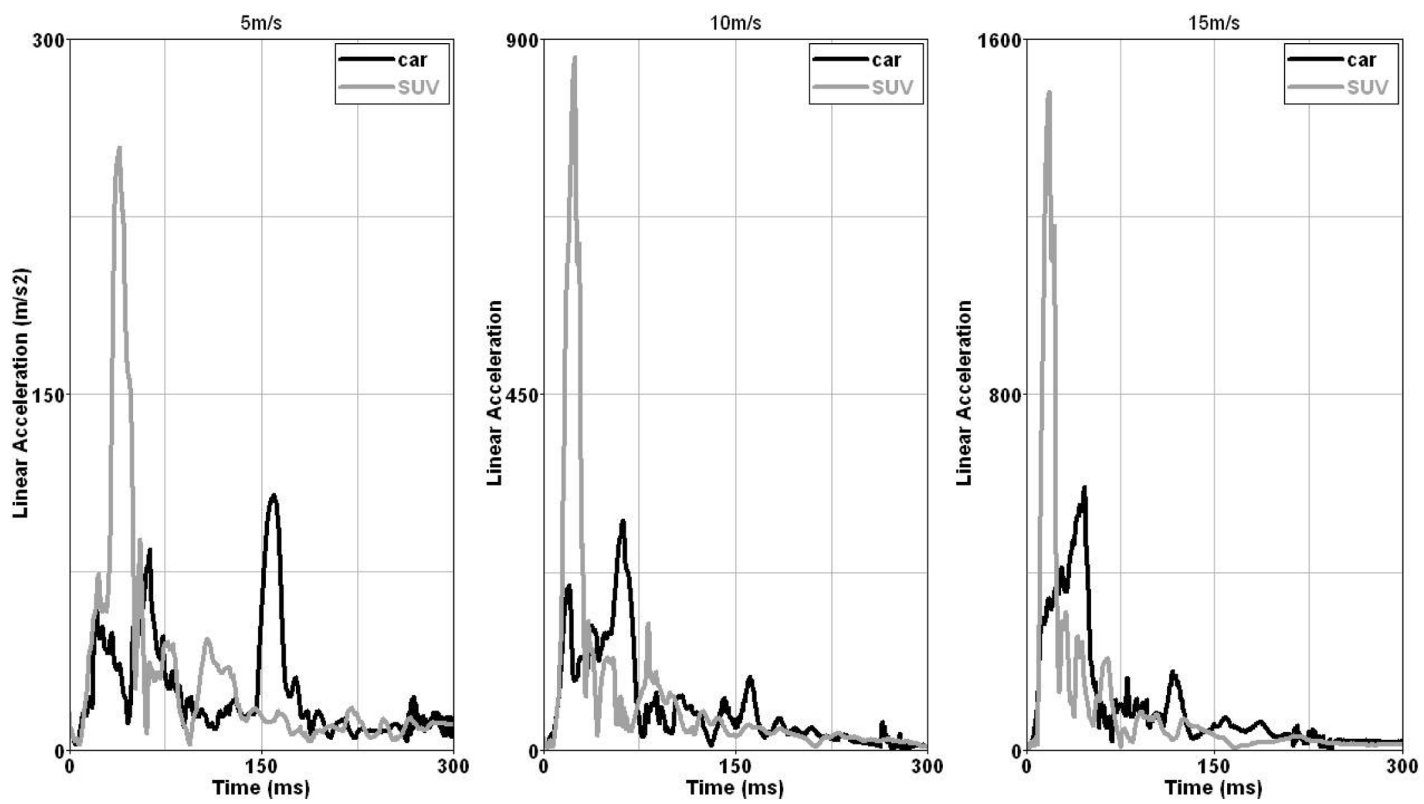

Fig. 11 Time histories of pelvis resultant accelerations for a side-facing pedestrian struck by a car/SUV at $18 \mathrm{~km} / \mathrm{h}(5 \mathrm{~m} / \mathrm{s}), 36 \mathrm{~km} / \mathrm{h}(10 \mathrm{~m} / \mathrm{s})$, and $54 \mathrm{~km} / \mathrm{h}(15 \mathrm{~m} / \mathrm{s})$

The validations are based on crash tests performed by Okamoto et al. [23] using the Polar II dummy in collisions with a car and an SUV at $40 \mathrm{~km} / \mathrm{h}$ $(11.1 \mathrm{~m} / \mathrm{s})$. The Polar dummy has been shown to reproduce cadaver kinematics adequately in impacts with both cars and SUVs $[\mathbf{2 4}, \mathbf{2 5}]$ and the multi-body simulations in the present work give a good prediction of Okamoto et al. tests (see Figs 2 to 4). These models therefore provide a sound basis for further analysis of pedestrian injuries from cars and SUVs.

Two pedestrian pre-impact stances have been analysed. From previous studies it is known that small alterations in pre-impact stance can have significant effects on subsequent kinematics [33-35]. For example, pre-impact transverse velocity of the pedestrian (walking or running) can result in the 

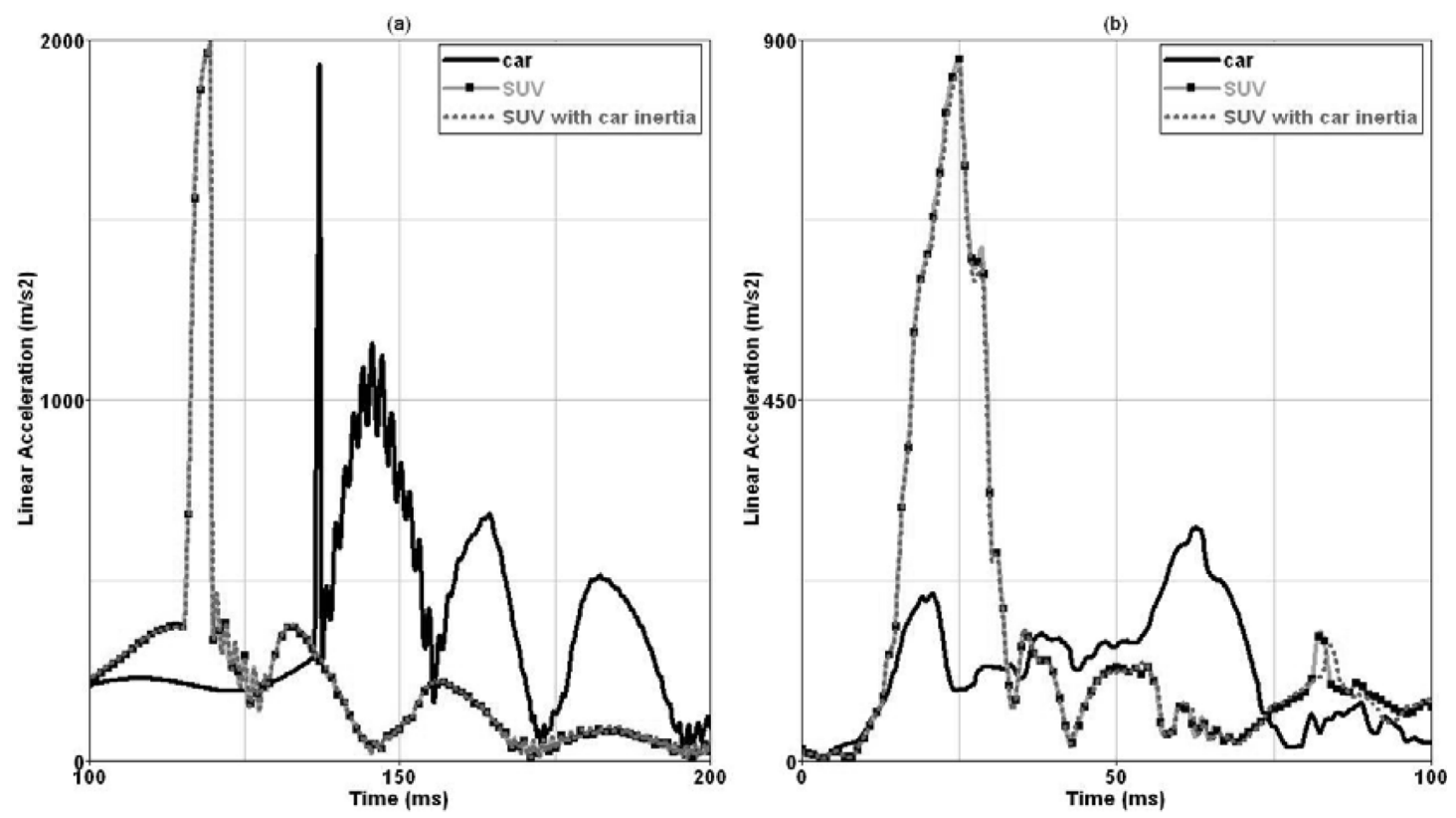

Fig. 12 The effects of vehicle mass and inertia on (a) head and (b) pelvis accelerations for a side-facing pedestrian at $10 \mathrm{~m} / \mathrm{s}$ impact

Table 2 Head injury predictions using the HIC criterion: injury reference level $=1000$

\begin{tabular}{lrrlrrrrr}
\hline & \multicolumn{3}{c}{ Facing front/back } & & \multicolumn{3}{c}{ Facing sideways } \\
\cline { 2 - 4 } & Car & SUV & $\begin{array}{l}\text { Head } \\
\text { response ratio }\end{array}$ & Car & SUV & $\begin{array}{l}\text { Head } \\
\text { response ratio }\end{array}$ \\
\hline $18 \mathrm{~km} / \mathrm{h}(5 \mathrm{~m} / \mathrm{s})$ & 284 & 885 & 3.1 & & 678 & 36 & 0.1 \\
$10 \mathrm{~m} / \mathrm{s}(36 \mathrm{~km} / \mathrm{h})$ & 1484 & 1294 & 0.9 & & 1220 & 1438 & 1.2 \\
$15 \mathrm{~m} / \mathrm{s}(54 \mathrm{~km} / \mathrm{h})$ & 4687 & 3447 & 0.7 & & 3942 & 2163 & 0.5 \\
\hline
\end{tabular}

Table 3 Chest injury predictions using the $3 \mathrm{~ms}$ acceleration criterion $\left(\mathrm{m} / \mathrm{s}^{2}\right)$ : injury reference level $=587 \mathrm{~m} / \mathrm{s}^{2}$

\begin{tabular}{|c|c|c|c|c|c|c|}
\hline & \multicolumn{3}{|c|}{ Facing front/back } & \multicolumn{3}{|c|}{ Facing sideways } \\
\hline & Car & SUV & $\begin{array}{l}\text { Chest } \\
\text { response ratio }\end{array}$ & Car & SUV & $\begin{array}{l}\text { Chest } \\
\text { response ratio }\end{array}$ \\
\hline $18 \mathrm{~km} / \mathrm{h}(5 \mathrm{~m} / \mathrm{s})$ & 112 & 178 & 1.6 & 76 & 124 & 1.6 \\
\hline $36 \mathrm{~km} / \mathrm{h}(10 \mathrm{~m} / \mathrm{s})$ & 213 & 346 & 1.6 & 145 & 367 & 2.5 \\
\hline $54 \mathrm{~km} / \mathrm{h}(15 \mathrm{~m} / \mathrm{s})$ & 492 & 441 & 0.9 & 312 & 546 & 1.8 \\
\hline
\end{tabular}

Table 4 Pelvis injury predictions using the peak acceleration criterion $\left(\mathrm{m} / \mathrm{s}^{2}\right)$ : injury reference level $=716 \mathrm{~m} / \mathrm{s}^{2}$

\begin{tabular}{lllllll}
\hline & \multicolumn{3}{c}{ Facing front/back } & & & \multicolumn{2}{c}{ Facing sideways } \\
\cline { 3 - 6 } \cline { 5 - 7 } & Car & SUV & $\begin{array}{l}\text { Pelvis } \\
\text { response ratio }\end{array}$ & Car & SUV & $\begin{array}{l}\text { Pelvis } \\
\text { response ratio }\end{array}$ \\
\hline $5 \mathrm{~m} / \mathrm{s}$ & 113 & 310 & 2.7 & 105 & 245 & 2.3 \\
$10 \mathrm{~m} / \mathrm{s}$ & 380 & 912 & 2.4 & 270 & 780 & 2.9 \\
$15 \mathrm{~m} / \mathrm{s}$ & 683 & 1573 & 2.3 & 536 & 1329 & 2.5 \\
\hline
\end{tabular}


Table 5 Abdomen injury predictions using the peak contact force criterion $N$ : injury reference level $=4.5 \mathrm{kN}$. Gaps $(-)$ correspond to cases where there was no direct impact with the abdomen

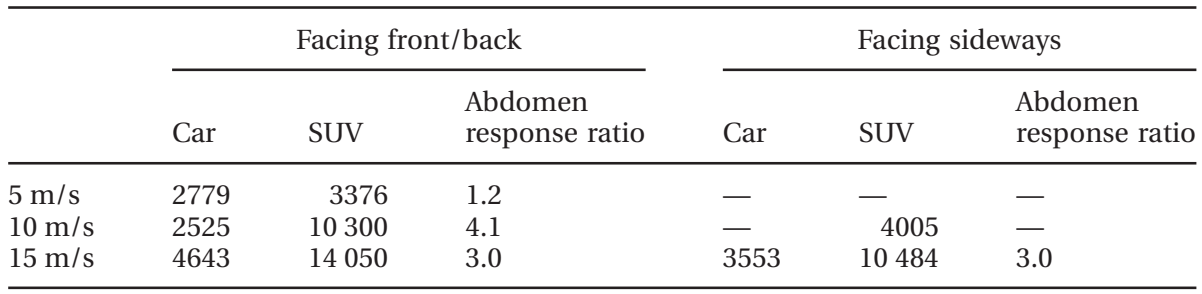

absence of a head impact on the vehicle for low car impact speeds, and leg positions at impact dictate the degree of axial rotation of the body for sidestruck pedestrians $[\mathbf{3 4}, \mathbf{3 5}]$. In addition, a single windscreen and a single bonnet force-deflection characteristic have been used to cover all contacts for the windscreen and bonnet regions respectively, despite the fact that there are localized regions of high stiffness in both of these structures. These modelling simplifications mean that the injury response ratios may be more valuable than the absolute injury predictions presented in Tables 2 to 5 .

\subsection{Pedestrian kinematics in car and SUV impacts}

In a typical car/pedestrian collision, the bumper and the leading edge of the bonnet strike the leg, causing the pedestrian to rotate on to the bonnet. This is confirmed by Figs 2, 6(a) and (c), 7(a) and (c), and $8(\mathrm{a})$ and (c). The bonnet or the windscreen then impacts the head and/or shoulders, following which vehicle braking usually results in the pedestrian separating from the vehicle. This sequence is well documented, but significant variations arise from the pedestrian pre-impact stance and walking/running speed, as well as the degree of braking, etc. $[\mathbf{3 4}, \mathbf{3 5}]$.

When an SUV strikes a pedestrian, the principal difference is that the higher bumper strikes the upper leg region. A consequence of this is that as the pedestrian engages the vehicle front, the pelvis and abdomen region rather than the upper leg are struck directly by the bonnet leading edge [36]. Head and/or shoulder strike then generally occurs with the bonnet rather than the windscreen. This sequence is clearly seen in Figs 3, 6(b) and (d), 7(b) and (d), and 8(b) and (d). There is therefore a far less eccentric impact with respect to the pedestrian centre of mass compared to the car/pedestrian impact. This means an increase in linear momentum imparted to the pedestrian by the SUV (and a decrease in rotational momentum) during primary impact. The loads sustained by the pelvis are substantially higher for the SUV compared to the car, and this is reflected in the much higher pelvis accelerations (see Fig. 11 and Table 4). Similarly, the upper torso region experiences higher accelerations in the SUV impact compared to the car impact (see Fig. 10 and Table 3).

In car/pedestrian impacts, the pedestrian wraps over the bonnet [Figs 2, 6(a) and (c), 7(a) and (c), and 8 (a) and (c)]. By contrast, for the SUV/pedestrian impact, the pelvis remains in contact with the bonnet leading edge/vehicle front and the upper and lower body regions rotate about the pelvis.

\subsection{Pedestrian injuries}

The predicted injuries to the head, thorax, pelvis, and abdomen from the present paper will now be discussed in the context of previous findings in this area. Given the real-world finding that 85 per cent of struck pedestrians are struck laterally [32], the results in Tables 2 to 5 for side-facing pedestrians are more important than those for forward-facing pedestrians.

\subsubsection{Head injury}

The deformation behaviour of the windscreen for the car impact and the bonnet for the SUV impact govern the respective pedestrian head loading for the two vehicle types. Figure 1 shows the sharp reduction in windscreen force after ca $10 \mathrm{~mm}$ deformation as the windscreen glass fails, followed by a further load rise as the laminate is stretched. In contrast, there is no sudden failure for the bonnet deformation, though there is a decrease in force after sufficient deformation causes the bonnet reinforcement to separate from the bonnet [26]. However, contact with stiff engine structures significantly contributes to head injury if there is insufficient clearance beneath the bonnet in the region of the head strike [37]. There are large variations in bonnet clearance distance and these stiff under-bonnet structures have therefore not been modelled in this study. Similarly, the windscreen edge is also very stiff [26], but contacts with the A pillar and/or scuttle have not been included in 
this work. The exact contact location of the head on the vehicle depends on the pedestrian pre-impact stance and movement $[\mathbf{3 4}, 35]$, and therefore only average windscreen and bonnet characteristics have been modelled.

Overall, there is a clear dependency of HIC on speed. At $5 \mathrm{~m} / \mathrm{s}$ the only moderate risk case is the SUV striking a forward-facing pedestrian $(\mathrm{HIC}=885)$. For the side-facing pedestrian, head contact with the vehicle is greatly reduced for the SUV impact at $5 \mathrm{~m} / \mathrm{s}$ because of the high contact with the pelvis and shielding of the head by the shoulders (see Figs 6(d) and 9). However, at $10 \mathrm{~m} / \mathrm{s}$ the head acceleration from the SUV impact is similar for the car and SUV cases for both the forward- and side-facing pedestrian (response ratios of 0.9 and 1.2 respectively). The reason for the big change in HIC values between 5 and $10 \mathrm{~m} / \mathrm{s}$ impact for the side-facing pedestrian struck by an SUV is that the protection offered by the shoulders at low speeds reduces quickly at higher speed impacts. In addition, windscreen fracture and the HIC formulation result in HIC scores for the car impact case remaining static between 5 and $9 \mathrm{~m} / \mathrm{s}$ impact speed. Above impact speeds of $9 \mathrm{~m} / \mathrm{s}$ stretching of the plastic laminate in the windscreen then acts to substantially increase the HIC score.

Head injuries are the principal cause of fatalities and a soft bonnet top can provide significant improvements to head injuries [6] when head contact is with the bonnet rather than the windscreen. Okamoto et al. [38] used finite element (FE) modelling and sled tests to compare pedestrian head impact conditions for both car and SUV impacts. However, they chiefly reported kinematic variations based on vehicle type and pedestrian stature and did not comment on injury risk.

Windscreen construction for SUVs compared to cars is similar. However, it is possible that there are increases in the bonnet stiffness in larger vehicles such as SUVs as stiffness generally correlates with mass. Simulations were performed with the bonnet stiffness increased by 20 per cent, and this resulted in commensurate increases in HIC scores for the
SUV impacts (see Table 6). These results show the importance for head injury of reducing bonnet stiffness in high-fronted vehicles. Nonetheless, at $15 \mathrm{~m} / \mathrm{s}$ for the side-facing pedestrian the car impact case still results in the highest HIC score (3942) due to the hard contact with the windscreen.

The majority of pedestrians are struck laterally [32] and therefore Table 2 suggests that, for collisions at $10 \mathrm{~m} / \mathrm{s}$, injuries from car contact are slightly worse for SUVs compared to cars (response ratio 1.2), but for 5 and $15 \mathrm{~m} / \mathrm{s}$ impacts the car results in higher head injuries (response ratios 0.1 and 0.5 respectively). In comparison, Roudsari et al. [19] reported that the likelihood of pedestrian head injuries in real-world accidents was minimally higher for LTVs (54 per cent) compared to cars (46 per cent). The mean collision speed in their study was $8.5 \mathrm{~m} / \mathrm{s}$ (with no speed difference between vehicle types), and the predicted HIC response ratio at this speed for side-struck pedestrians is 1.9. This high ratio reflects the manner in which head acceleration varies with windscreen failure.

Finally, Roudsari et al. [19] reported that ground contact accounted for only 7 per cent of head injuries in car impact cases compared to 39 per cent of head injuries for LTV impacts. This result is supported by the present study, where for side-facing pedestrians the SUV impacts generally resulted in head-toground contact before the upper body hit the ground. This was not found for the car impact cases. Although the pedestrian ground impact is highly variable [33], these results indicate that the shape of SUVs increases the likelihood of a direct head impact with the ground. Overall, these head injury predictions are in good agreement with the real-world findings of Roudsari et al. [19].

\subsubsection{Chest injury}

Table 3 shows the chest injury predictions. At $5 \mathrm{~m} / \mathrm{s}$ impact for both side- and forward-facing pedestrians, the SUV/car response ratio is 1.6 . At $10 \mathrm{~m} / \mathrm{s}$, the SUV/ car response ratios are 1.6 and 2.5 for the forwardand side-facing cases respectively, indicating a higher

Table 6 Head injury predictions using the HIC criterion for a car, SUV, and SUV with $20 \%$ stiffer bonnet

\begin{tabular}{|c|c|c|c|c|c|c|}
\hline & \multicolumn{3}{|c|}{ Facing front/back } & \multicolumn{3}{|c|}{ Facing sideways } \\
\hline & Car & SUV & $\begin{array}{l}\text { SUV with } 20 \% \\
\text { stiffer bonnet }\end{array}$ & Car & SUV & $\begin{array}{l}\text { SUV with } 20 \% \\
\text { stiffer bonnet }\end{array}$ \\
\hline $18 \mathrm{~km} / \mathrm{h}(5 \mathrm{~m} / \mathrm{s})$ & 284 & 885 & 1065 & 678 & 36 & 40 \\
\hline $10 \mathrm{~m} / \mathrm{s}(36 \mathrm{~km} / \mathrm{h})$ & 1484 & 1294 & 1587 & 1220 & 1438 & 1701 \\
\hline $15 \mathrm{~m} / \mathrm{s}(54 \mathrm{~km} / \mathrm{h})$ & 4687 & 3447 & 3974 & 3942 & 2163 & 2596 \\
\hline
\end{tabular}


risk for the chest from SUVs at this speed. Matsui et al. impacted the Polar pedestrian dummy laterally with a car at $40 \mathrm{~km} / \mathrm{h}$ and concluded there is negligible chest loading in such cases [39]. Table 3 shows good agreement with this finding.

For the forward-facing pedestrian at the $15 \mathrm{~m} / \mathrm{s}$ impact, chest loadings for the car and SUV impacts are similar (response ratio 0.9). For the side-facing case, the SUV score is much higher for the SUV (response ratio 1.8) and the chest acceleration at this speed approaches the tolerance level. These results compare well with the findings of Roudsari et al. [19] who reported a 37 per cent chance of thorax injuries for LTVs compared to a 20 per cent chance of thorax injuries for car impacts.

\subsubsection{Pelvis and abdomen injury}

In all configurations there is a substantially higher risk for the pelvis in the SUV impact compared to the car impact. The pelvis response ratios for the forward- and side-facing pedestrian cases range between 2.3 and 2.9, indicating a much higher pelvic risk for SUV impacts compared to cars. In staged accidents using cars striking cadavers, Ishikawa et al. recorded no pelvic fractures [22]. Subsequent simulations of these cadaver tests [40] showed pelvis and chest accelerations that were only about half as large as thigh and head accelerations, indicating that the pelvis and chest are relatively protected structures in standard impacts between cars and adult pedestrians. This can be seen in cases (a) and (c) in Figs 6, 7, and 8, which show the standard wrap projection sequence between a pedestrian and a passenger vehicle. In these cases, the pelvis is clearly shielded from the brunt of the impact.

Edwards and Green analysed severely injured pedestrians in the UK and found that in cases where pelvic fracture does occur, although these are not inherently life threatening, their occurrence is well correlated with pedestrian morbidity and mortality [41]. They stated that this is because the high loads required for a pelvic fracture result in serious accompanying injuries such as disruption of internal organs. Lawrence analysed the impulse imparted to the upper leg/pelvis of pedestrian dummies for a variety of vehicle bonnet designs and found that a higher bonnet height results in a more central impact [12]. In particular, raising the bonnet leading edge height by $250 \mathrm{~mm}$ nearly doubled the impulse. Thus pelvic fractures may also be correlated with severe injury or death because a pelvic impact means load transfer at the pedestrian centre of gravity. A primary impact to the pelvis from an SUV allows no load amelioration due to rotation as occurs when the lower limbs are struck first in a car impact.

Table 5 shows the direct abdomen contact force. The SUV impacts are much more severe in all cases (response ratio 1.2-4.1). At impact speeds of $10 \mathrm{~m} / \mathrm{s}$ and greater, the abdomen contact force for the SUV impacts is above the $4.5 \mathrm{kN}$ threshold reported by Talantikite et al. [30], indicating a substantial risk for the abdomen from the leading edge structures of high-fronted vehicles. These results compare well with the findings of Roudsari et al. [19], who reported a 33 per cent chance of abdomen injuries for LTVs compared to an 18 per cent chance of abdomen injuries for car impacts.

\subsection{Vehicle mass effects versus vehicle geometry effects}

Mass, geometry, and stiffness are the principal factors that may differ between cars and SUVs. However, it can be shown from fundamental considerations that the mass difference between cars and SUVs is not significant for pedestrian impacts. Consider the two cases of a stationary pedestrian (mass $M_{\text {ped }}$ ) struck by either a car or an SUV (mass $M_{\text {veh }}$ ) at a speed $v_{\text {col }}$. Assuming a common postimpact velocity at the impact location (i.e. plastic impact), a radius of gyration $k$ for the pedestrian, and a vertical height difference $h$ between the pedestrian centre of gravity (cg) and the bonnet leading edge, then the pedestrian cg velocity after primary impact is $[\mathbf{4 2}]$

$$
v_{\text {ped_cg }}=\left[\frac{M_{\text {veh }} k^{2}}{k^{2}\left[M_{\text {veh }}+M_{\text {ped }}\right)+h^{2} M_{\text {veh }}}\right] v_{\text {col }}
$$

For an adult pedestrian mass of $75 \mathrm{~kg}$ and height $L=1.75 \mathrm{~m}$, and using generalized relationships between the radius of gyration $k$ and the pedestrian cg height $h_{\text {cg }}$ compared to the overall height $L$ from [43]

$$
k=0.23 L \quad \text { and } \quad h_{\mathrm{cg}}=0.57 \mathrm{~L}
$$

this yields $h_{\mathrm{cg}}=1.0 \mathrm{~m}$ and $k=0.4 \mathrm{~m}$. Then, to compare the mass effects alone, and hence ignoring the shape differences between vehicles and SUVs by assuming a nominal value for $h$ of $0.15 \mathrm{~m}$ and using mean car and SUV masses of 1275 and $1625 \mathrm{~kg}$ respectively [17], equation (1) shows that for the car impact, the pedestrian centre of gravity velocity following primary impact is 83 per cent of the collision speed for the car impact and 84 per cent for the SUV impact. Clearly, when only accounting for the mass difference between cars and SUVs, there is a negligible effect on momentum transfer in the 
primary impact. This is verified by Fig. 13 where the resultant head and pelvis acceleration time histories for the $10 \mathrm{~m} / \mathrm{s}$ SUV impact on a side-facing pedestrian are given for the two cases where (a) the SUV has its correct inertia properties and (b) the SUV has the inertia properties of the passenger car. There is a negligible difference between these two cases. Mizuno and Kajzer reached a similar conclusion using real-world data from Japan [44].

However, approximating the bonnet leading edge heights for typical cars and SUVs at 0.7 and $1.0 \mathrm{~m}$ respectively, the height difference $h$ between the bonnet leading edge and the pedestrian centre of gravity is $0.3 \mathrm{~m}$ for cars and $0 \mathrm{~m}$ for SUVs. Application of equation (1) shows that the pedestrian centre of gravity velocity following primary impact is now only 62 per cent of the impact speed for a car impact but 96 per cent of the impact speed for an SUV impact. These results concur approximately with Lawrence's finding that raising the bonnet leading edge height from 600 to $850 \mathrm{~mm}$ nearly doubled the impulse [12].

Therefore, an important effect of the bonnet edge height is that the pedestrian is struck more centrally and hence closer to the centre of gravity, which lies at about 57 per cent of body height, i.e. in the region of the pelvis [43]. This increases the impact efficiency and the overall momentum transfer from the vehicle to the pedestrian is greater. Lawrence noticed this phenomenon in the 1980s in the context of bonnet heights of passenger cars [12], but this has not been reported with respect to SUVs.

\subsection{The future}

Recently, designers have attempted to improve SUV front-end design by removing additional hazards such as bull bars and by creating more curved bonnets with a lower primary impact location. This is a very positive development and has resulted in improvement in EuroNCAP ratings for some SUVs. However, Snedeker et al. [45] and Kuehn et al. [46] have correctly raised the question of whether the simplified EEVC tests used in EuroNCAP can accurately represent the three-dimensional nature of a vehicle/pedestrian impact. The findings of this paper suggest that more detailed tests are necessary to assess vehicle front-end shape.

\section{CONCLUSIONS}

A review of real-world accident data and the detailed models presented in this paper show that pedestrian risk when struck by SUVs compared to cars is higher and the body regions at risk are different. The injury predictions for the head, chest, and pelvis are in good agreement with the real-world findings of Roudsari et al. [19]. The results show that, on average, head injuries are similar or slightly lower from contact with SUVs compared to cars, but injuries to the mid-body regions are substantially higher. The primary reason for the increased hazard to pedestrians from SUVs is the high front shape of the bumper and bonnet. The mass difference between cars and SUVs is not very significant for pedestrian injury causation. The location of the primary impact is such that the midbody region is directly struck in an SUV/pedestrian collision, allowing less rotation of the body. This means that for pedestrians struck by SUVs there is the combination of a harder primary impact which occurs directly with the critical mid-body region. Lowering the bumper and bonnet and reducing bonnet stiffness for SUVs would help to reduce injuries to these mid-body regions.

\section{REFERENCES}

1 Traffic safety facts 2002, National Highway Traffic Safety Administration, US Department of Transportation, Washington, DC, 2003.

2 Reducing traffic injuries through vehicle safety improvements - the role of vehicle design, European Transport Safety Council, Brussels, 1993.

3 Mohan, D., Kajzer, J., Bawa-Bhalla, W., Chawla, A., and Sarabjit, S. Impact modelling studies for a three wheeled scooter taxi. In Proceedings of the IRCOBI Conference, Brunnen, Switzerland, 1995, pp. 325-337.

4 Jacobs, G. and Thomas, A. Africa road safety review: Final Report. US Department of Transport, Federal Highway Administration, 2000.

5 Walz, F. H., Hoefliger, M., and Fehlmann, W. Speed limit reduction from 60 to $50 \mathrm{~km} / \mathrm{h}$ and pedestrian injuries. In Proceedings of the 27th Stapp Car Crash Conference, San Diego, 1983, SAE paper 831625, pp. 311-318.

6 Liu, X. J., Yang, J. K., and Lovsund, P. A study of influences of vehicle speed and front structure on pedestrian impact responses using mathematical models. Traff. Injury Prev., 2002, 3(31), 42.

7 Anderson, R. W. G., McClean, A. J., Farmer, M. J. B., Lee, B. H., and Brooks, C. G. Vehicle travel speeds and the incidence of fatal pedestrian crashes. Accid. Analysis Prev., 1997, 29(5), 667-674.

8 Wood, D. P. Pedestrian impact, injury and accident causation. In Automotive engineering and litigation (Eds G. A Peters and B. J. Peters), 1991, vol. 4, ch. 3 (John Wiley, New York).

9 Otte, D. Severity and mechanism of head impacts in vehicle to pedestrian accidents. In Proceedings of the IRCOBI Conference, Isle of Man, 2001, pp. 329-341.

10 Priorities for EU motor vehicle safety design, European Transport Safety Council, Brussels, 2001. 
11 Niederer, P. and Schlumpf, M. Influence of vehicle geometry on impact pedestrian kinematics. SAE paper 841663, 1984.

12 Lawrence, G. The influence of vehicle shape on pedestrian impact energies and its application to sub-system tests. In Proceedings of the 12th ESV Conference, Gothenburg, 1989.

13 PricewaterhouseCoopers European Quarterly Review. New car volume trends, 2005 (Eurocarprice, Aston Sandford).

14 Lefler, D. E. and Gabler, H. C. The fatality and injury risk of light truck impacts with pedestrians in the United States. Accid. Analysis Prev., 2004, 36(2), 295-304.

15 Ashton, S. J. and Mckay, G. M. Benefits from changes in vehicle exterior design: field accident and experimental work in Europe. SAE paper 830626, 1983.

16 Roudsari, B., Mock, C., Kaufmann, R., Grossman, D. Henary, B., and Crandall, J. Pedestrian crashes: higher injury severity and mortality rate for light truck vehicles compared with passenger vehicles. Injury Prev., 2004, 10, 154-158.

17 Ballesteros, M. F., Dischinger, P. C., and Langenberg, P. Pedestrian injuries and vehicle type in Maryland, 1995-1999. Accid. Analysis Prev., 2004, 36(1), 73-81.

18 Longhitano, D., Henary, B., Bhalla, K., Ivarsson, J., and Crandall, J. Influence of vehicle body type on pedestrian injury distribution. SAE paper 2005-011876, 2005.

19 Roudsari, B., Mock, C., and Kaufmann, R. An evaluation of the association between vehicle type and the source and severity of pedestrian injuries. Traff. Injury Prev., 2005, 6, 185-192.

20 Madymo database manual, 2004 (TNO, Delft).

21 Coley, G., De Lange, R., de Oliviera, P., NealSturgess, C. E., and Happee, R. Pedestrian human body model validation using detailed real-world accidents. In Proceedings of the IRCOBI Conference, Isle of Man, 2001, pp. 89-101.

22 Ishikawa, H., Kajzer, J., and Schroeder, G. Computer simulation of impact response of the human body in vehicle pedestrian accidents. In Proceedings of the 37th Stapp Vehicle Crash Conference, San Antonio, 1993.

23 Okamoto, Y., Akiyama, A., Okamoto, M., and Kikuchi, Y. A study of the upper leg component tests compared with pedestrian dummy tests. In Proceedings of the ESV Conference, Nagoya, 2001.

24 Akiyama, A., Okamoto, M., and Rangarajan, N. Development and application of the new pedestrian dummy. In Proceedings of the ESV Conference, Nagoya, 2001

25 Kerrigan, J., Kam, C., Murphy, D., Bose, D., Ivarsson, J., and Crandall, J. Kinematic comparison of the Polar II and PMHS in pedestrian impacts with a sport utility vehicle. In Proceedings of the IRCOBI Conference, Prague, 2005, pp. 159-174.

26 Mizuno, K. and Kajzer, J. Head injuries in vehicle pedestrian impact. SAE paper 2000-01-0157, 2000, pp. 24-40.
27 Hertz, E. A note on the head injury criterion as a predictor of skull fracture. In Proceedings of the 37th AAAM Conference, San Antonio, 1993.

28 Haffner, M. Synthesis of pelvic fracture criteria for lateral impact loading. In Proceedings of the 11th ESV Conference, 1985, SAE paper 856022, National Highway Traffic Safety Administration.

29 Zhu, J. Y., Cavanaugh, J. M., and King, A. I. Pelvic biomechanical response and padding benefits in side impact based on a cadaveric test series. SAE paper 933128, 1993.

30 Talantikite, Y., Brun-Cassan, F., Lecoz, J., and Tarriere, C. Abdominal injury protection in side impact - injury mechanisms and protection criteria. In Proceedings of the IRCOBI Conference, Eindhoven, 1993, pp. 131-144.

31 Schmitt, K. U., Niederer, P., and Walz, F. Trauma biomechanics: introduction to accidental injury, 2004 (Springer, Berlin).

32 Yang, J. K., et al. Pedestrian position definition, deliverable D8, HUMOS2 Project, GRD-2001-50053, 2003.

33 Bhalla, K., Montazemi, P., Crandall, J., Yang, J., Liu, X., Dokko, Y., Takahashi, Y., Kikuchi, Y., and Longhitano, D. Vehicle impact velocity prediction: trade offs between throw formulae, crash simulators and detailed multi-body modelling. In Proceedings of the IRCOBI Conference, Munich, September 2002.

34 Simms, C. K. and Wood, D. P. Pedestrian impact: The effect of pedestrian motion on head contact forces with the ground. In Proceedings of the IRCOBI Conference, Prague, 2005.

35 Simms, C. K., Wood, D. P., and Walsh, D. G. Confidence limits for impact speed estimation from pedestrian projection distance. Int. J. Crashworthiness, 2004, 9(2), 219-228.

36 Simms, C. K. and O'Neill, D. Sport utility vehicles and vulnerable road users. Br. Med. J., 2005, 331 , 787-788.

37 Pritz, H. B. Experimental investigation of pedestrian head impacts on hood and fenders of production vehicles. SAE paper 830055, 1983.

38 Okamoto, Y., Sugimoto, T., Enomoto, K., and Kikuchi, J. Pedestrian head impact conditions depending on the vehicle front shape and its construction - full model simulation. Traff. Injury Prev., 2003, 4, 74-82.

39 Matsui, Y., Wittek, A., and Tanahashi, M. Pedestrian kinematics due to impacts by various passenger cars using full scale dummy. Int. J. Veh. Safety, 2005, 1(1/2/3), 64-84.

40 Yang, J. K. and Lovsund, P. Development and validation of a human body mathematical model for simulation of vehicle-pedestrian collisions. In Proceedings of the IRCOBI Conference, Hannover, 1997.

41 Edwards, K. J. and Green, J. F. Analysis of the interrelationship of pedestrian leg and pelvis injuries. In Proceedings of the IRCOBI Conference, Sitges, 1999.

42 Wood, D. P. Application of a rigid body impact model to the pedestrian-vehicle collision. In 
Proceedings of the IRCOBI Conference, Bron, 1988, pp. 241-252.

43 Wood, D. P. and Walsh, D. G. Pedestrian forward impact projection. Int. J. Crashworthiness, 2002, 7(3), 285-305.

44 Mizuno, K. and Kajzer, J. Compatibility problems in frontal, side, single car collisions and car-topedestrian accidents in Japan. Accid. Analysis Prev., 1999, 31, 381-389.

45 Snedeker, J., Walz, F., Muser, M., Lanz, C., and Schroeder, G. Assessing femur and pelvis injury risk in car-pedestrian collisions, comparison of full body PMTO impacts, and a human body finite element model. In Proceedings of the ESV Conference, Washington, 2005.

46 Kuehn, M., Froeming, R., and Schindler, R. An advanced testing procedure for pedestrian car collisions. Int. J. Veh. Safety, 2005, 1(1/2/3), 65-99.

\section{APPENDIX}

Minor alterations to the Madymo pedestrian model hip and ankle stiffness were required to prevent gimbal lock in the hip and ankle restraints used in the model. The Madymo pedestrian contact definitions were utilized, but the leg force deflection function was slightly altered to prevent very large penetrations (see Figs 13 and 14).

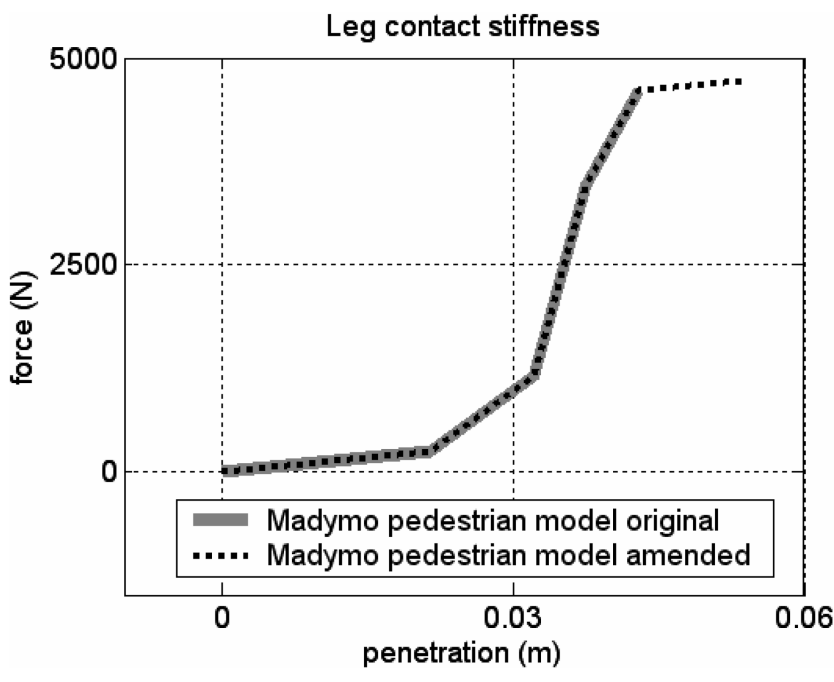

Fig. 13 Amended pedestrian leg contact function used in this paper compared to the original Madymo pedestrian model function

\section{Hysteresis in vehicle pedestrian impacts}

In all cases the hysteresis slope was $1^{8}$. The combined force deformation characteristics of both contacting surfaces were used in all cases except for the vehicle/ head contacts, where the vehicle deformation
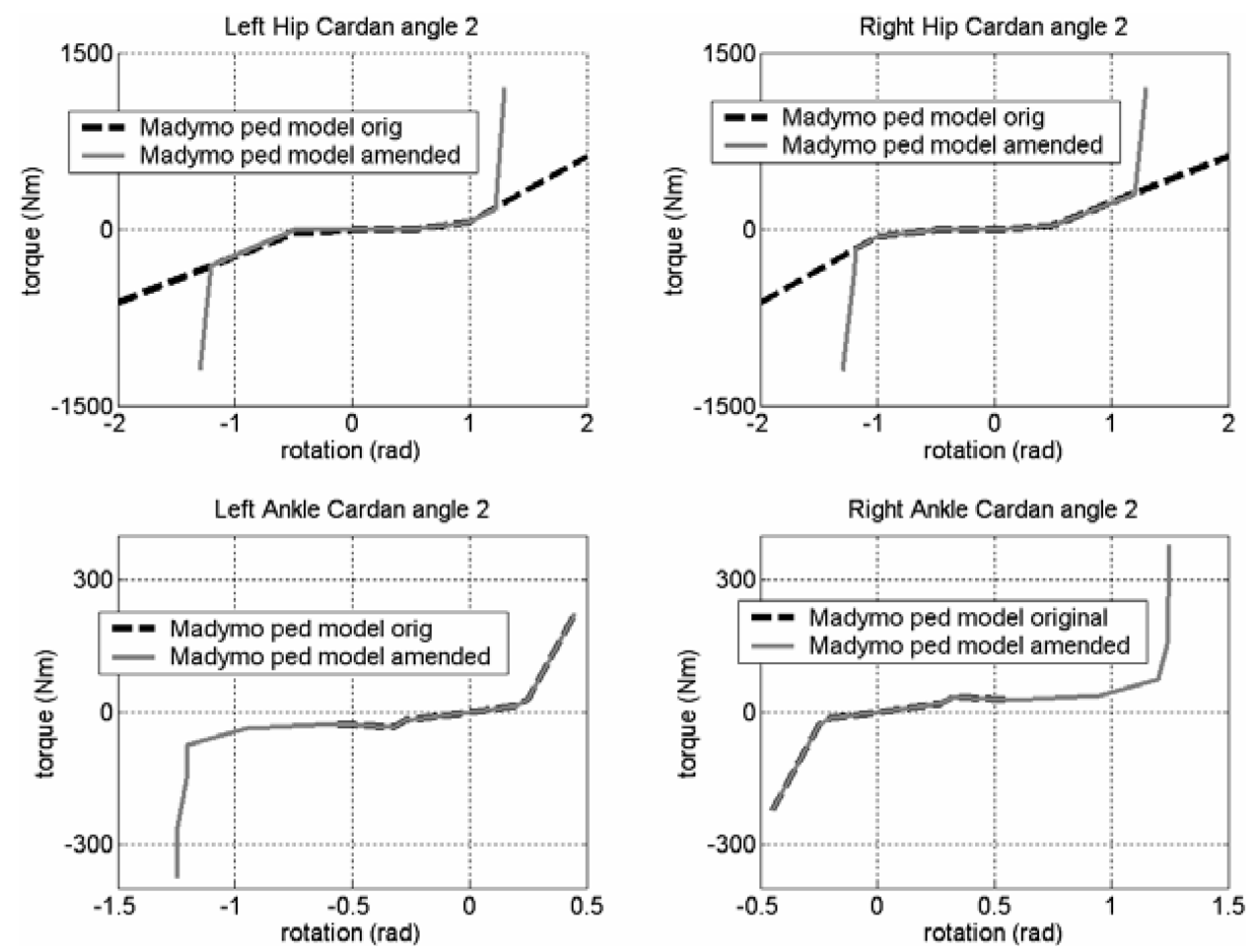

Fig. 14 Amended pedestrian ankle and hip Cardan restraint functions to prevent gimbal lock used in this paper compared to the original Madymo pedestrian model function 


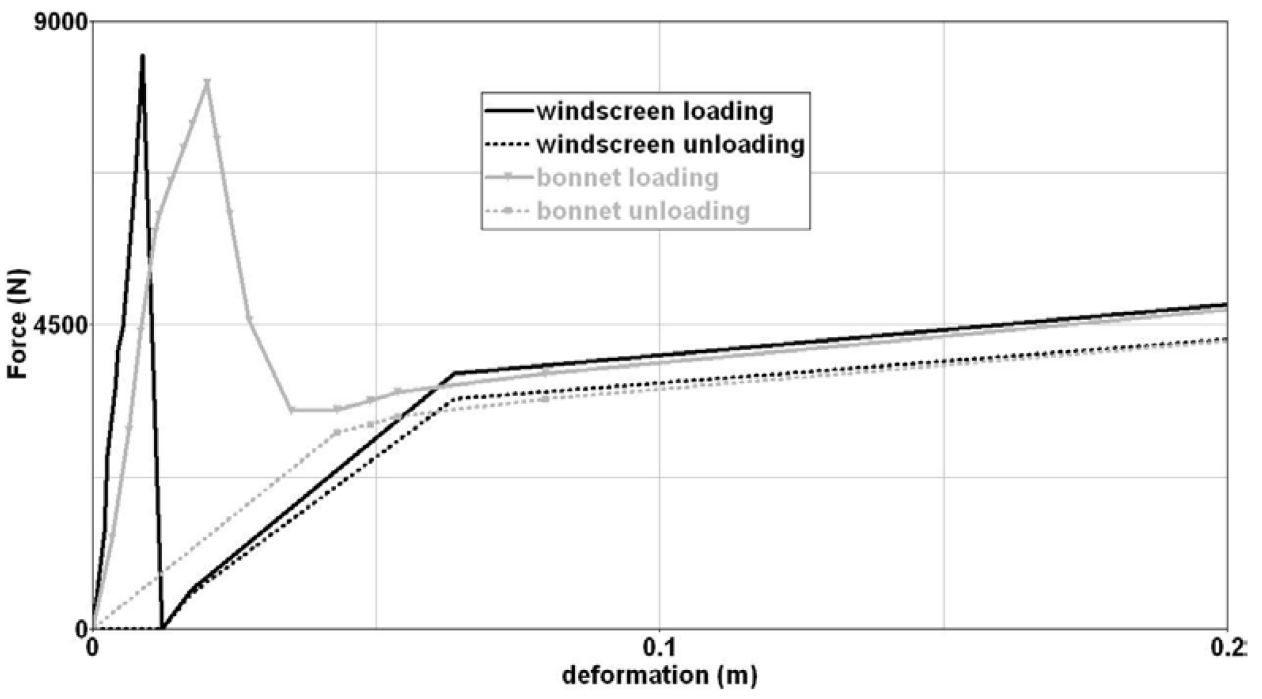

Fig. 15 Windscreen and bonnet loading and unloading functions (adapted from Mizuno and Kajzer [26])

characteristics only were used. This was necessary to ensure correct functioning of the hysteresis loop in Madymo. The 'vehicle front' contact consisted of the bumper (upper and lower), bonnet leading edge, and bonnet surfaces.
For the bumper and bumper leading ledge, the unloading force penetration function was 10 times less stiff than the loading function. For the bonnet and windscreen, the loading and unloading functions are given in Fig. 15. 